\title{
P10s-PADRE vaccine combined with neoadjuvant chemotherapy in ER-positive breast cancer patients induces humoral and cellular immune responses
}

\author{
Issam Makhoul'1,6, Saddam Mohammed Ibrahim ${ }^{2,7}$, Muhammad Abu-Rmaileh ${ }^{4}$, \\ Fariba Jousheghany ${ }^{2}$, Eric R. Siegel ${ }^{3}$, Lora J. Rogers ${ }^{1}$, John J. Lee ${ }^{2}$, Sergio Pina- \\ Oviedo$^{2}$, Ginell R. Post ${ }^{2}$, J. Thaddeus Beck ${ }^{5}$, Thomas Kieber-Emmons ${ }^{2}$ and Behjatolah \\ Monzavi-Karbassi ${ }^{2,6}$ \\ ${ }^{1}$ Department of Medicine, University of Arkansas for Medical Sciences, Little Rock, AR 72205, USA \\ ${ }^{2}$ Department of Pathology, University of Arkansas for Medical Sciences, Little Rock, AR 72205, USA \\ ${ }^{3}$ Department of Biostatistics, University of Arkansas for Medical Sciences, Little Rock, AR 72205, USA \\ ${ }^{4}$ Department of Internal Medicine, University of Texas Southwestern, Dallas, TX 75390, USA \\ ${ }^{5}$ Highland Oncology Group, Fayetteville, AR 72703, USA \\ ${ }^{6}$ Winthrop P. Rockefeller Cancer Institute, University of Arkansas for Medical Sciences, Little Rock, AR 72205, USA \\ 7UnivLyon, Université Claude Bernard Lyon 1, Villeurbanne 69100, France \\ Correspondence to: Behjatolah Monzavi-Karbassi, email: karbassi@uams.edu
}

Keywords: cancer vaccine; peptide mimotopes; combination therapy; breast cancer

Received: August 24, $2021 \quad$ Accepted: September 11, $2021 \quad$ Published: October 26, 2021

Copyright: ( 2021 Makhoul et al. This is an open access article distributed under the terms of the Creative Commons Attribution License (CC BY 3.0), which permits unrestricted use, distribution, and reproduction in any medium, provided the original author and source are credited.

\section{ABSTRACT}

Breast cancer patients diagnosed with HR+/HER2- tumors face a persistent risk of distant recurrence long after completion of their treatment. Strategies to induce anti-tumor immune responses could complement standard-of-care therapies for these patients. The current study was performed to examine the feasibility, safety and immunogenicity of adding P10s-PADRE to standard-of-care chemotherapy in HR+ / HER2 - early-stage breast cancer patients. Twenty-five subjects were treated in a single-arm Phase Ib clinical trial. Five different immunization schedules were considered to evaluate the feasibility of eliciting an immune response. The primary immunogenicity endpoint was antibody titer. The expression of several activation markers on natural killer (NK) cells and serum concentrations of Th1/Th2 cytokines were also examined. The percentage of tumor-infiltrating lymphocytes (TILs) was determined. Antibody response was superior in schedule C where 3 weekly immunizations preceded the first dose of chemotherapy. A significant change in CD16, NKp46 and CD94 expression levels on NK cells and a rise in serum content of IFN-Y was observed after treatment. Schedule $C$ showed an increase in TILs in residual lesions. The combination therapy is safe and immunogenic with treatment schedule $\mathrm{C}$ being immunologically promising. Randomized trials focused on long-term survival outcomes are needed to evaluate clinical benefits.

\section{INTRODUCTION}

HR+/HER2 - breast cancer remains the most common form of breast cancer in the United States [1]. The positive prognostic effect of ER + status is limited to 5 years after diagnosis, as the prognosis of $\mathrm{HR}+$ patients becomes worse than that of triple-negative or HER2+ patients among those alive after 5 years since diagnosis [2-4]. Apparently, the current paradigm of endocrine therapy with or without chemotherapy has not been effective for a considerable number of these patients $[5,6]$. Neoadjuvant chemotherapy (NAC) has become 
a standard practice for treatment of high-risk localized breast cancer, and pathological complete response (pCR) to NAC has been a trusted surrogate to assess longterm survival benefits. However, for HR+ breast cancer patients, compared to patients with triple-negative or HER2 + tumors, the benefit of NAC in terms of pCR is limited, as pCR to neoadjuvant treatment is observed less frequently in $\mathrm{HR}+$ patients $[7,8]$. Residual tumors at the time of surgery in patients treated with NAC are immunesuppressed as evidenced by having a lower abundance of TILs, decreased fraction of immune effectors and increased density of immune-suppressive cells compared to baseline levels [9]. HR+ tumors are notorious for their low immunogenicity, low percentage of TILs, and lack of correlation of TIL levels with favorable clinical outcomes [8]. However, in a study with about 30 years of followup, in HR+/HER2- premenopausal breast cancer patients, high infiltration of TILs was a favorable prognostic factor regarding disease recurrence or breast cancer-specific death [10]. In another study, the increase in stromal TILs in residual disease in a patient population, $79 \%$ of which had $\mathrm{HR}+$ disease, was associated with improved recurrencefree survival [11]. Therefore, a rational combination therapy that enhances the immune-stimulatory properties of NAC, can provide long-term survival benefits for this patient population. Development of new strategies aimed at active induction of anti-tumor immune responses and improving immunogenicity of such immunologically cold tumors could increase the effectiveness of standard approaches and improve long-term survival benefits.

We have developed carbohydrate-mimetic peptides (CMPs) as a means to augment immune responses to tumor-associated carbohydrate antigens [12, 13]. We have brought one CMP, called P10s-PADRE, to the clinic $[14,15]$. We performed a Phase I clinical trial with the P10s-PADRE vaccine in Stage IV breast cancer patients. Immunization induced anti-peptide and anti-glycan antibody responses whereby the induced antibodies were cytotoxic in a Caspase 3-dependent manner [15]. The immunization of breast cancer patients with P10sPADRE proved feasible, tolerable and immunologically efficacious. After more than 8 years of follow-up, 4 out of 6 vaccinated subjects from the Phase I clinical trial are still alive, with 3 of them in stable condition and 1 subject still in remission. Moreover, we observed that P10s-PADRE-induced immune serum triggered chemosensitivity to paclitaxel in the HR+ZR-75-1 cell line [15], which suggests that combining the P10sPADRE vaccine with chemotherapy regimens that include taxanes may prove beneficial in treating breast cancer patients.

In our preclinical studies, we observed that natural killer (NK) cells were involved in P10s-mediated tumor eradication, and that the data generated in the Phase I clinical trial of P10s-PADRE indicate activation of NK cells, as shown by increased expression of the NKp46
(NCR1, natural cytotoxicity triggering receptor 1) marker on circulating NK cells [16]. NK cells are $\mathrm{CD}^{-} / \mathrm{CD}^{+} 6^{+}$ (NCAM1) lymphocytes that constitute about $10 \%$ of peripheral blood lymphocytes, and are considered a component of the innate immune system that can control tumors and microbial infections through their ability to produce cytokines like IFN- $\gamma$ and TNF- $\alpha$ as well as their cytolytic activity [17]. The potential of increased NK-mediated immune response has been associated with rejection of lenalidomide-resistant multiple myeloma tumor [18] and improved clinical response in neuroblastoma patients [19]. Additionally for a vaccine with antibody-dependent anti-tumor mechanisms of action, CD16 receptor is considered a potent activator of NK cells and the main mediator of antibody-dependent cell-mediated cytotoxicity (ADCC).

The data derived from a Phase $\mathrm{Ib}$ clinical trial in HR+/HER2- breast cancer patients shown here indicate that combining P10s-PADRE with NAC is feasible and immunogenic.

\section{RESULTS}

\section{Subject characteristics, adverse events and feasibility}

Characteristics of subjects enrolled and vaccinated are summarized in Table 1. Adverse events (AEs) were graded and evaluated at each visit throughout the duration of the study (about 16 months after application of the first dose of the vaccine or chemotherapy). A total of 626 AEs were recorded, with 42 AEs attributed as definite, probable, or possible relationship to the vaccine (Table 2). Twenty-seven AEs were described as grades 1 and 2 injection-site reactions that included redness, rash, induration, itching, burning, warmth, and sometimes pain. Only two AEs were described as grade 3. They included one severe abdominal distention and one severe fatigue. No grade $\geq 4$ AEs were observed. All patients completed their treatment schedule. The data suggest that adding P10s-PADRE vaccine to NAC was feasible and well-tolerated, with injection-site irritation as the only repetitive $\mathrm{AE}$.

\section{P10s-PADRE immunization in combination with chemotherapy induced antibody response}

In the current clinical trial, we used anti-peptide antibody response as a marker to choose the best schedule for combination therapy. Blood specimens were collected at various weeks during each schedule's period, and fold change in anti-peptide antibody titer was measured (Table 3). We have reported that serum antibodies become detectable as early as week 4 of the study, peak at week 7 and stay stable up to at least the 24th week [13]. In the current study, surgery was conducted between weeks 
Table 1: Characteristics of subjects accrued

\begin{tabular}{|c|c|c|c|c|c|c|c|c|c|}
\hline $\begin{array}{c}\text { Subject } \\
\text { study } \\
\text { number }\end{array}$ & Race & Age & $\mathbf{P S}^{*}$ & $\begin{array}{l}\text { Tumor } \\
\text { stage, } \\
\text { Tumor } \\
\text { grade }\end{array}$ & $\begin{array}{c}\text { Tumor } \\
\text { type }^{+}\end{array}$ & $\begin{array}{c}\text { Tumor } \\
\text { size at } \\
\text { baseline } \\
(\mathrm{cm})^{\#}\end{array}$ & $\begin{array}{c}\text { Tumor } \\
\text { size after } \\
\text { treatment } \\
(\mathrm{cm})^{\mathrm{s}}\end{array}$ & $\begin{array}{c}\text { Clinical } \\
\text { LN } \\
\text { status at } \\
\text { baseline }^{\#}\end{array}$ & $\begin{array}{c}\text { Pathologic } \\
\text { LN status } \\
\text { after } \\
\text { treatment }^{\$}\end{array}$ \\
\hline $\mathbf{A 1}$ & $\mathrm{W}$ & 58 & 0 & IIB, 1 & A & 4.2 & 0.2 & N1 & N1 \\
\hline A2 & W & 64 & 0 & IIIB, 2 & A & 3.2 & 0.5 & N0 & N0 \\
\hline $\mathbf{A} 3$ & W & 40 & 0 & IIB, 2 & B & 2.6 & 2 & N1 & N1 \\
\hline A4 & $\mathrm{W}$ & 74 & 1 & IIA, 2 & B & 2.5 & 4.4 & N0 & N0 \\
\hline A5 & $\mathrm{W}$ & 59 & 0 & IIB, 2 & $\mathrm{~B}$ & 2 & 0.2 & N1 & $\mathrm{N} 1$ \\
\hline B1 & $\mathrm{W}$ & 55 & 0 & IIA, 3 & B & 3.7 & 0 & N0 & N0 \\
\hline B2 & W & 49 & 0 & IIIB, 3 & A & 4 & 0.5 & N1 & N0 \\
\hline B3 & AA & 55 & 0 & IIA, 2 & A & 3.3 & 3.7 & N0 & N0 \\
\hline B4 & $\mathrm{W}$ & 67 & 0 & IIB, 2 & A & 2.8 & 1.5 & N1 & N0 \\
\hline B5 & $\mathrm{AA}$ & 39 & 0 & IIIA, 2 & A & 6.5 & 0.1 & N1 & $\mathrm{N} 1$ \\
\hline $\mathrm{C1}$ & $\mathrm{W}$ & 63 & 0 & IIIB, 1 & A & 7 & 3.5 & N1 & N1 \\
\hline $\mathrm{C} 2$ & W & 60 & 0 & IIIB, 2 & B & 3.7 & 3.5 & N0 & $\mathrm{N} 1$ \\
\hline $\mathrm{C} 3$ & W & 40 & 0 & IIB, 3 & A & 2.7 & 1.1 & N1 & N1 \\
\hline $\mathrm{C} 4$ & W & 71 & 0 & IIB, 2 & A & 7 & 7.5 & No & N1 \\
\hline C5 & W & 54 & 0 & IIA, 3 & B & 3.7 & 0.3 & N0 & N0 \\
\hline D1 & W & 54 & 0 & IIB, 2 & A & 4.9 & 2.5 & N0 & N0 \\
\hline D2 & W & 70 & 0 & IIA, 3 & B & 1.3 & 0 & N0 & N0 \\
\hline D3 & W & 45 & 0 & IIB, 2 & A & 4.6 & 4 & N1 & N1 \\
\hline D4 & W & 70 & 0 & II, 3 & B & 1 & 0.4 & N1 & N1 \\
\hline D5 & $\mathrm{W}$ & 35 & 1 & III, 2 & $\mathrm{~B}$ & 7 & 0.5 & N1 & No \\
\hline E1 & $\mathrm{W}$ & 45 & 1 & IIB, 2 & $\mathrm{~A}$ & 1.4 & 3 & N1 & N0 \\
\hline E2 & $\mathrm{W}$ & 67 & 0 & IIA, 2 & B & 2.4 & 1.7 & N0 & N1 \\
\hline E3 & W & 45 & 0 & IIIB, 3 & B & 2.5 & 2.4 & N0 & N0 \\
\hline E4 & W & 32 & 0 & IIA, 3 & B & 2.7 & 0.2 & N0 & N0 \\
\hline E5 & W & 28 & 0 & IIB, 3 & B & 0.8 & 0 & N1 & N1 \\
\hline
\end{tabular}

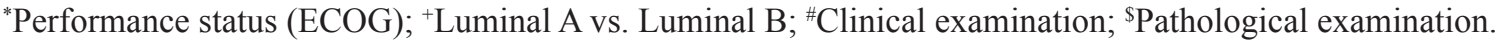

26 and 33, depending on the combination schedule (Supplementary Table 2). As a criterion for successful immune activation in the designed protocol, we defined a response to consist of at least a 4-fold increase in antibody titer after immunization that repeats in two separate weeks by week 13 to 16 , depending on the schedule. Any combination schedule with at least 4 out of 5 subjects responding was considered as an acceptable schedule for future clinical trials. According to the data summarized in Table 3, both schedules $\mathrm{C}$ and $\mathrm{E}$ qualified as acceptable, with each of them having 4 subjects responding to the immunization by week 16 . Further comparisons of the magnitude of antibody response (Figure 1) indicate that mean fold increase in antibody titer of schedule $\mathrm{C}$ (48-fold increase) is significantly higher than the 4-fold limit $(P=0.021)$. The data suggest that subjects enrolled in schedule $\mathrm{C}$ generated a more consistent and robust antibody response, therefore schedule $\mathrm{C}$ appears as the schedule of choice for future combination therapy. However, continued analysis of blood samples collected suggests that, in patients enrolled on the other schedules, serum antibodies may start to appear later, close to surgery or even later (i.e., please see Table 3 , first and second subjects of schedule B).

\section{Combination therapy affected the expression levels of NK-cell markers}

In the Phase I clinical trial, we explored activation of NK cells by analyzing the expression of several NKcell markers and observed a statistically significant increase in expression of NKp46 on CD3-/CD56 blood lymphocytes [16]. Therefore, we isolated peripheral blood mononuclear cells and used median fluorescence 
Table 2: Number of AEs (number of patients, pts) by grade, where relationship to vaccine is definite, probable, or possible

\begin{tabular}{|c|c|c|c|c|c|c|c|c|}
\hline \multirow{3}{*}{ Body system } & \multirow{3}{*}{ Adverse event } & \multicolumn{6}{|c|}{ Severity scale grade } & \multirow{3}{*}{$\begin{array}{l}\text { All } \\
\text { AEs }\end{array}$} \\
\hline & & \multicolumn{2}{|c|}{ 1: Mild } & \multicolumn{2}{|c|}{ 2: Moderate } & \multicolumn{2}{|c|}{ 3: Severe } & \\
\hline & & AEs & (pts) & AEs & (pts) & AEs & (pts) & \\
\hline Gastrointestinal disorders & Abdominal distension & - & - & 1 & $(1)$ & 1 & $(1)$ & 2 \\
\hline \multirow{3}{*}{$\begin{array}{l}\text { General disorders and } \\
\text { administrative site conditions }\end{array}$} & Fatigue & 1 & (1) & 2 & (2) & 1 & (1) & 4 \\
\hline & Injection site reaction & 23 & (23) & 4 & (3) & - & - & 27 \\
\hline & intermittent fatigue & 1 & $(1)$ & 2 & $(2)$ & - & - & 3 \\
\hline $\begin{array}{l}\text { Musculoskeletal and } \\
\text { connective tissue disorders }\end{array}$ & $\begin{array}{l}\text { Musculoskeletal and connective } \\
\text { tissue disorders - other, sharp pains } \\
\text { in random spots }\end{array}$ & - & - & 1 & (1) & - & - & 1 \\
\hline \multirow[t]{2}{*}{ Nervous system disorders } & Headache & - & - & 1 & (1) & - & - & 1 \\
\hline & Intermittent headaches & - & - & 1 & $(1)$ & - & - & 1 \\
\hline \multirow{2}{*}{$\begin{array}{l}\text { Reproductive system and } \\
\text { breast disorders }\end{array}$} & Intermittent left breast pain & 1 & (1) & - & - & - & - & 1 \\
\hline & $\begin{array}{l}\text { Reproductive system and breast } \\
\text { disorders - other, burning } \\
\text { sensation left breast }\end{array}$ & 1 & (1) & - & - & - & - & 1 \\
\hline Vascular disorders & $\begin{array}{l}\text { Vascular disorders - other, night } \\
\text { sweats }\end{array}$ & 1 & (1) & - & - & - & - & 1 \\
\hline All AEs & & 28 & $(28)$ & 12 & $(11)$ & 2 & (2) & 42 \\
\hline
\end{tabular}

intensity (MFI) to determine the expression of CD16, CD69, NKp46 and CD94 markers in the $\mathrm{CD}^{-} / \mathrm{CD} 56^{+}$ NK population. Change in MFI of the markers in postimmune cells compared to pre-immune cells was plotted (Figure 2A). We observed that the MFI of NKp46 increased from 612 to $1201(96 \%, P \leq 0.0001)$ and that the MFI of CD94 increased from 1377 to $2070(50 \%, P \leq$ 0.0001 ) in response to treatment when the entire study population was analyzed. Contrary to NKp46 and CD94 expression, CD16 (FcyRIII) expression dropped 23\% after immunization $(P=0.0076)$. No significant change in the expression of CD69 $(P=0.4389)$ was observed. Treatment schedule affected the change in the expression of CD16 and CD94 with a tendency towards significance (Figure 2B). Schedule C displays a high and positive MFI for CD16 expression levels and the lowest MFI for CD94 expression levels in response to therapy. Because of the robust antibody production and the elevated expression

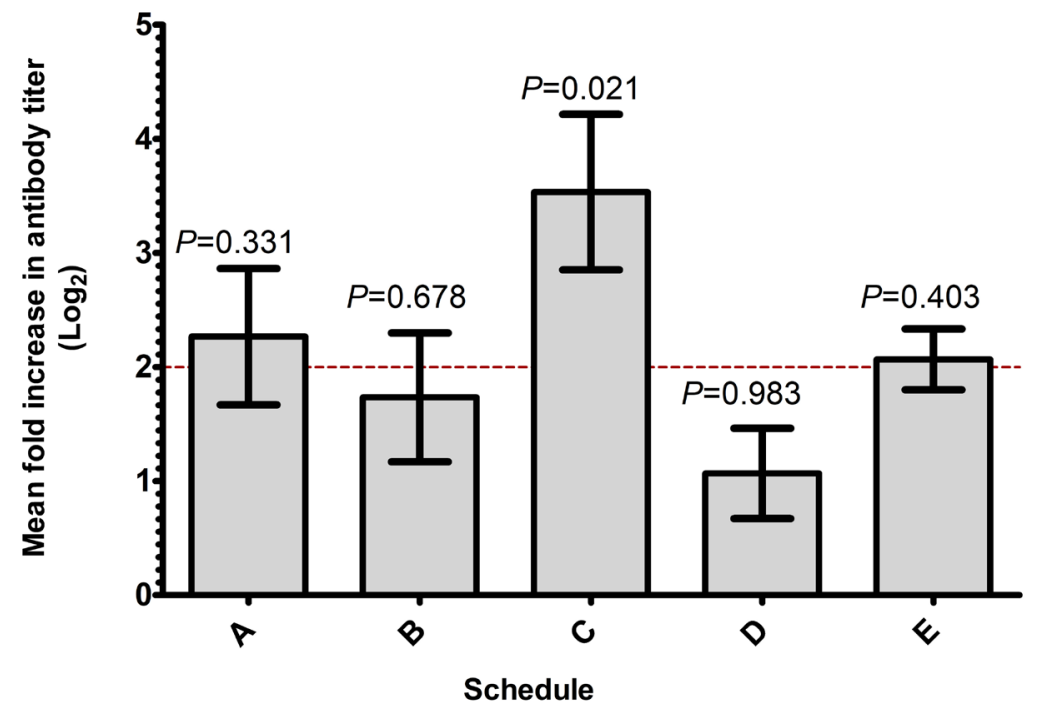

Figure 1: Schedule C produces more consistent and superior antibody titer. Mean fold increase in antibody titers for treatment schedules A through E is shown. Fold increase in anti-P10s peptide titer of 3 consecutive weeks, early during the course of therapy, for all subjects in each schedule was log2-transformed and analyzed using 1-sided $t$-test comparing the mean fold increase with 4 fold. 
Table 3: Fold increase in anti-peptide IgG titer in subjects enrolled in 5 schedules

\begin{tabular}{|c|c|c|c|c|c|c|c|}
\hline Group & W-4 & W-7 & W-10 & W-13 & W-22 & W-46 & W-70 \\
\hline $\mathbf{A}$ & 4 & 32 & 32 & 16 & 16 & 16 & 8 \\
\hline A & 1 & 4 & 4 & 2 & 2 & 2 & 2 \\
\hline A & NA & NA & 64 & 32 & 16 & 16 & 32 \\
\hline A & 1 & 1 & 1 & N/A & N/A & N/A & N/A \\
\hline \multirow[t]{2}{*}{ A } & 1 & 1 & 1 & 1 & 1 & 1 & 1 \\
\hline & W-7 & W-10 & W-13 & W-16 & W-22 & W-46 & W-70 \\
\hline B & 1 & 1 & 1 & 1 & 1 & 8 & 8 \\
\hline B & 1 & 1 & 1 & 1 & 4 & 8 & 8 \\
\hline B & 4 & 16 & 16 & 64 & 32 & 16 & N/A \\
\hline B & 1 & 1 & 2 & 2 & 2 & 1 & 2 \\
\hline \multirow[t]{2}{*}{ B } & 16 & 32 & 32 & 32 & 8 & 4 & 4 \\
\hline & W-7 & W-10 & W-13 & W-16 & W-25 & W-49 & W-73 \\
\hline C & 8 & 32 & 32 & 4 & 4 & 2 & 2 \\
\hline C & 4 & 4 & 4 & 32 & 32 & 32 & N/A \\
\hline C & 8 & 16 & 32 & 64 & 64 & 64 & N/A \\
\hline C & 1 & 1 & 1 & 1 & 1 & 8 & 4 \\
\hline \multirow[t]{2}{*}{ C } & 64 & 256 & 256 & 256 & 64 & 16 & 32 \\
\hline & W-5 & W-8 & W-11 & W-14 & W-23 & W-47 & W-71 \\
\hline D & 1 & 4 & 4 & 8 & N/A & 8 & N/A \\
\hline D & 1 & 1 & 1 & 1 & 1 & 2 & 2 \\
\hline D & 8 & 16 & 16 & 8 & 8 & 16 & N/A \\
\hline D & 1 & 1 & 1 & 1 & 2 & 2 & 2 \\
\hline \multirow[t]{2}{*}{ D } & 2 & 1 & 1 & 2 & 1 & 1 & 16 \\
\hline & W-6 & W-9 & W-12 & W-15 & W-24 & W-48 & W-72 \\
\hline $\mathbf{E}$ & 4 & 8 & 32 & N/A & N/A & NA & N/A \\
\hline $\mathbf{E}$ & 2 & 4 & 4 & 8 & 8 & 16 & 8 \\
\hline $\mathbf{E}$ & 2 & 8 & 4 & N/A & N/A & N/A & N/A \\
\hline $\mathbf{E}$ & 4 & 4 & 4 & N/A & N/A & N/A & N/A \\
\hline $\mathbf{E}$ & 4 & 2 & 2 & N/A & N/A & N/A & N/A \\
\hline
\end{tabular}

Antibody titer was determined in pre-immune samples and at various times (weeks, W) after immunization. The fold increase in antibody titer (relative to pre-immune levels) is reported.

levels of CD16, schedule C was compared against all other schedules one-by-one and others combined. One-by-one comparisons of schedule $\mathrm{C}$ with other schedules suggest a significant increase in CD16 and a significantly different lower levels of CD94 expression compared to schedules B and $\mathrm{A}$, respectively (Figure $2 \mathrm{~B}$ ). Comparison of schedule $\mathrm{C}$ with other schedules combined revealed a statistically significant separation between the two regarding CD16 (median of 2999 vs. -6008) and CD94 (median of 346 vs. 849) expression (Figure 2C). The data suggest that schedule $\mathrm{C}$ may affect NK cells differently than other schedules. With the most robust antibody response and the upregulation of the Fc receptors, it is expected that schedule $\mathrm{C}$ would be the most effective in antibodymediated targeting and killing of cancer cells.

The expression of CD69 in T (CD3+/CD56-) and NKT (CD3+/CD56+) cells was examined in pre- and postimmune samples. No significant change in MFI of CD69 and no treatment effect was observed (data not shown).

\section{Combination therapy stimulated production of cytokines}

Robust IgG production and activation of NK-cell populations after treatment suggests that immunization with P10s-PADRE may affect cytokine production. 
The serum concentration of an array of cytokines was measured. The cytokines IL-4 and IL-12 either were not detected or recorded values were below the lower limit of detection. IL-2 and IL-13 contained 5 and 11 undetectable values, respectively, and therefore were removed from further analyses. IL-1 $\beta$ data were also removed from analysis because of a high inter-experimental variability. We detected IL-6, IL-10, IFN- $\gamma$, and TNF- $\alpha$ in 24 available serum samples out of 25 . Further analysis of the entire cohort indicated significant increases in median concentration of IFN- $\gamma$ (from 4.9 to $10.4 \mathrm{pg} / \mathrm{ml}$ ), IL-6 (from 0.76 to $1.17 \mathrm{pg} / \mathrm{ml}$ ), IL-10 (from 0.18 to $0.36 \mathrm{pg}$ /
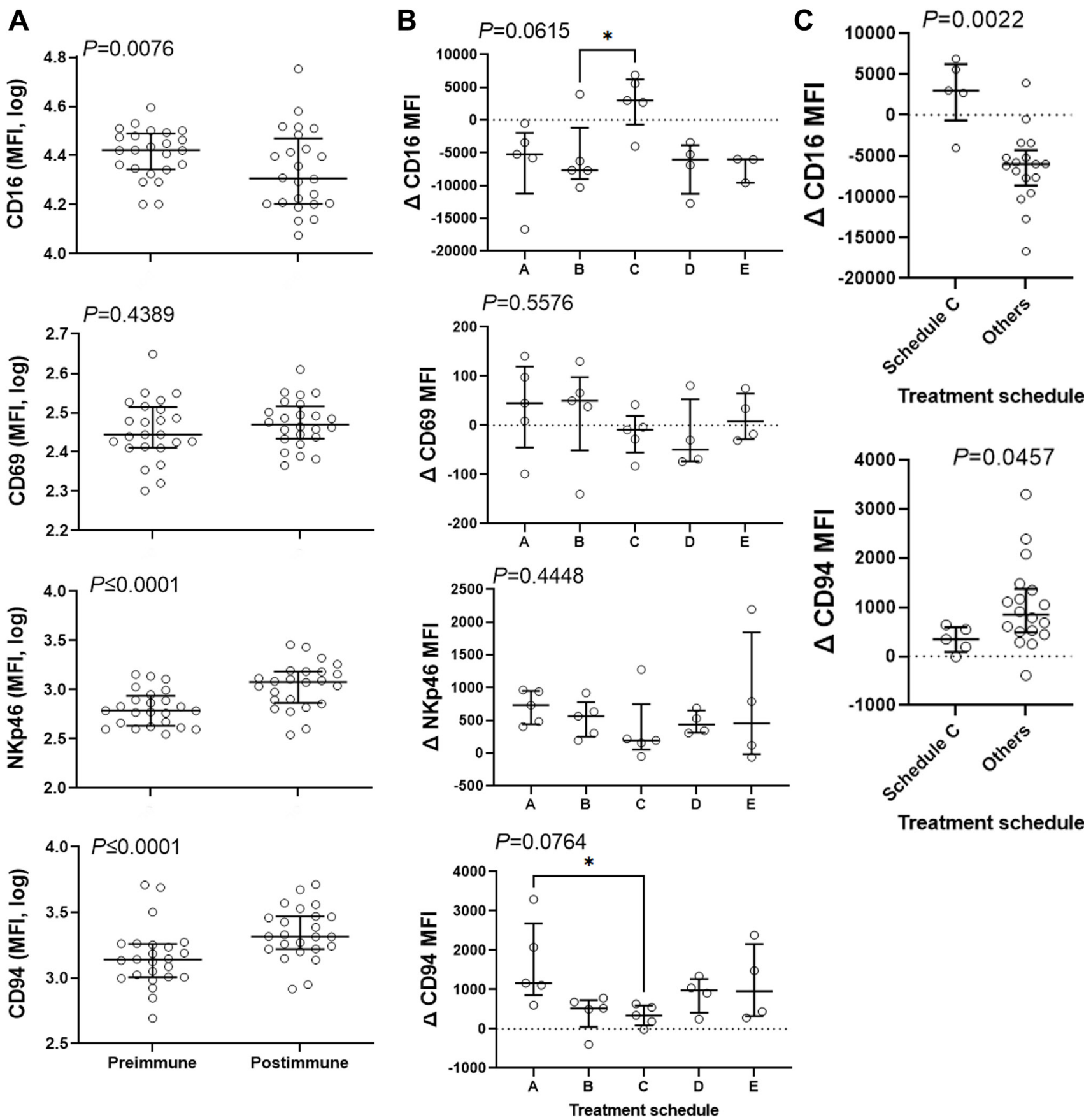

Treatment schedule

Figure 2: Combination therapy affects expression of NK-cell markers. CD3-negative CD56-positive population was gated and the expression levels of CD16, CD69, NKp46, and CD94 was determined. (A) Median Fluorescence Intensity (MFI) for these markers was measured in pre and postimmune samples and was plotted for 23 subjects. Data were analyzed with 2-sided paired Wilcoxon's signed-rank test. (B and C) The effect of treatment schedule (the timing of administration of the vaccine relative to chemotherapy) on the therapyinduced change in the expression levels of the above markers was analyzed. Data were analyzed with Kruskal-Wallis (B) or 2-sided MannWhitney (C) tests. Kruskal-Wallis test was followed by Dunn's multiple comparisons test comparing schedule C with other schedules. Bars show median and interquartile range. ${ }^{*}$, significant at $P \leq 0.05$. 
$\mathrm{ml}$ ), and TNF- $\alpha$ (from 2.95 to $3.6 \mathrm{pg} / \mathrm{ml}$ ) in post-immune compared to pre-immune serum samples (Figure 3A). Only IFN- $\gamma$ increase was affected by treatment schedule, with schedule B showing a median increase of $10.16 \mathrm{pg} / \mathrm{ml}$ in post immunization serum compared to schedule D showing a median drop of $1.29 \mathrm{pg} / \mathrm{ml}$ in serum content of IFN- $\gamma$ (Figure 3B). No significant difference between schedule C and other schedules one-by-one or combined was detected.
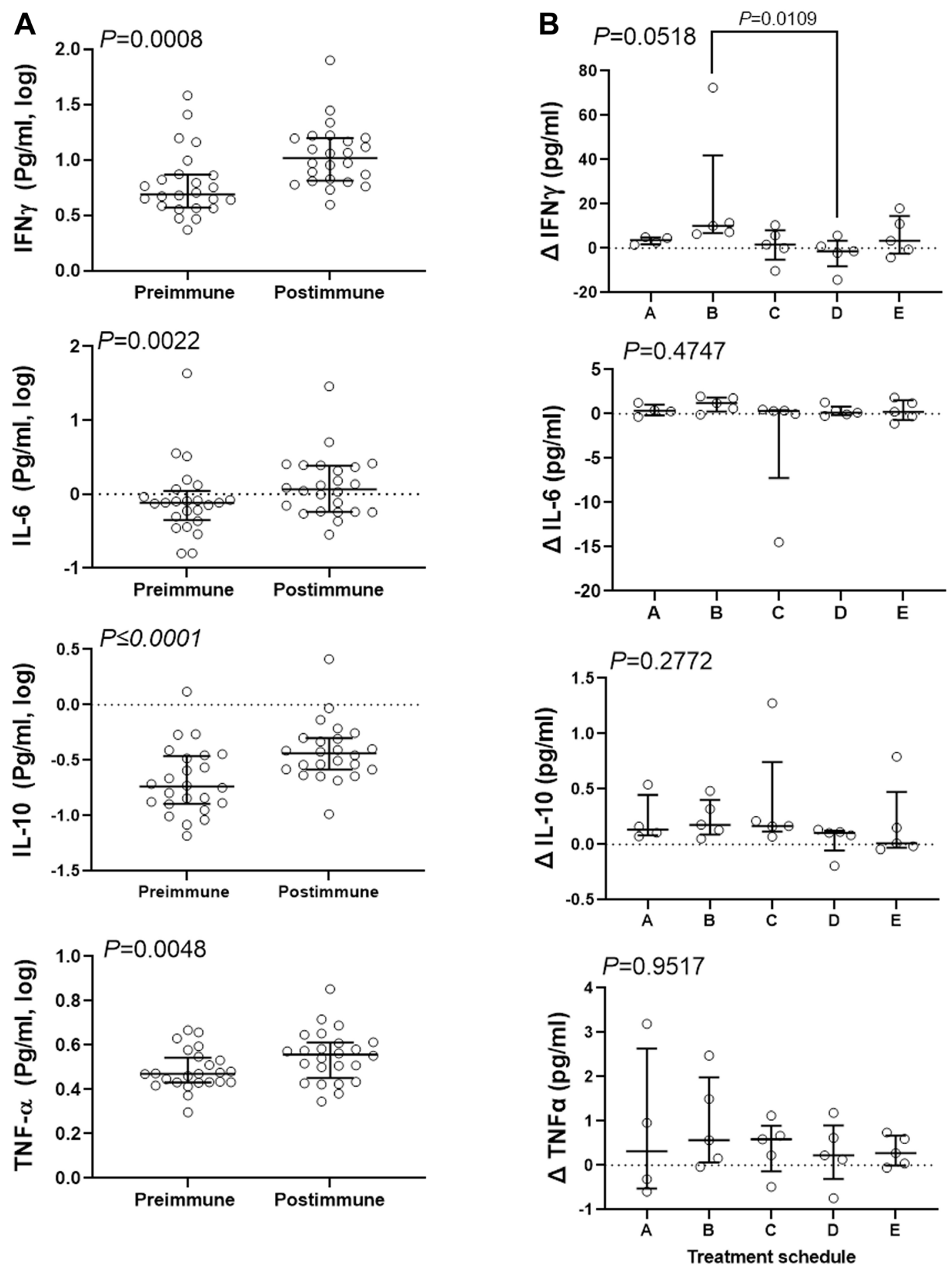

Figure 3: Combination therapy resulted in increase of serum content of several inflammatory cytokines. Concentration of the cytokines was determined in pre- and post-immune serum samples for 24 subjects and analyzed to determine the combination effect in general (A), and the effect of treatment schedule in particular (B). Data were analyzed with 2-sided paired Wilcoxon's signed-rank (A) or Kruskal-Wallis (B) tests. Kruskal-Wallis test was followed by Dunn's multiple comparisons test comparing median change of IFN $\gamma$ content of schedules $\mathrm{B}$ and $\mathrm{C}$ with other schedules. Bars show median and interquartile range. 


\section{T cells are the major component of infiltrating tumor lymphocytes (TILs)}

Because of the significance of TILs in treatment efficacy [20] and because our data suggests activation of NK cells, we examined the effect of combination therapy on immune response in the tumor microenvironment. We assessed stromal TILs using pre-treatment core biopsies and post-treatment surgical biopsies. Only 17 out of 25 subjects were included. We lost 5 subjects due to lack of post-treatment specimen because of complete or close to complete eradication of their primary tumors, and we lost 3 other subjects due to the absence of consent for tissue staining. TILs were quantified and summarized for the 17 subjects (Figure 4A). $\mathrm{H}$ and $\mathrm{E}$ images representative of the scoring approach are shown (Supplementary Figure 1). The treatment schedule significantly affect percentage of stromal TILs (Figure 4A, $P=0.0325$ ). Pair-wise comparisons of schedule $\mathrm{C}$, median change of +5 , with other schedules one-by-one shows a significant difference only with schedule $\mathrm{D}$, median change of $-10(P=0.0444)$. The change in TIL percentages after treatment in schedules $C$, median change of +5 , showed a tendency towards significance when compared with other
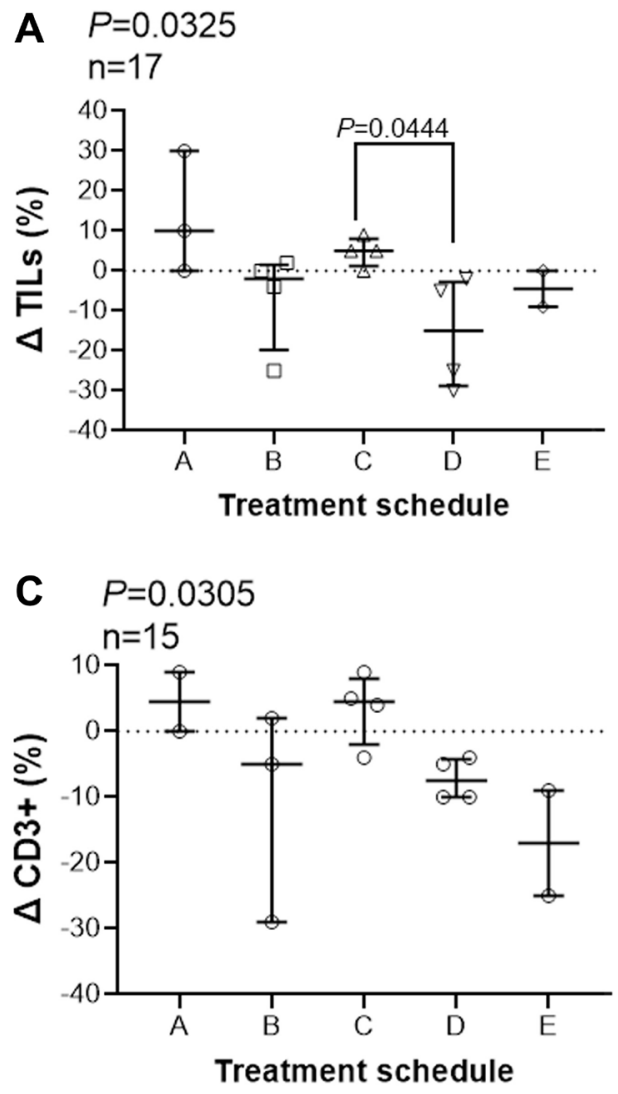

schedules combined, with median change of -2 (Figure 4B, $P=0.0819)$. More tissue slides were prepared and stained to detect predominant immune cell type among TILs. We did not observe NK (CD56+)-cell infiltration among the 17 subjects evaluated; however, the majority of TILs were CD3+ lymphocytes (Figure 4C). A similar pattern to TILs was observed when we examined the change in quantity of CD3+ T-cells $(P=0.0305$, Figure $4 C)$. Schedule $\mathrm{C}$ showed a positive change in in infiltrating $\mathrm{CD} 3+$ cells in residual lesions after treatment, median +4.5 , that was significantly different than the median change in subjects treated in other schedules combined, median -2 (Figure 4D). We observed statistically significant change in the quantity of TILs and CD3+ cells after treatment affected by treatment schedule, showing a potential role for the peptide immunization. The data suggest that treatment schedule C may also positively affect infiltration of lymphocytes.

\section{Tumor response to combination therapy}

To explore the potential impact of combination therapy on the tumor, pCR status and change in tumor size were investigated as clinical outcomes. We observed that combination therapy across the 5 cohorts resulted in

B

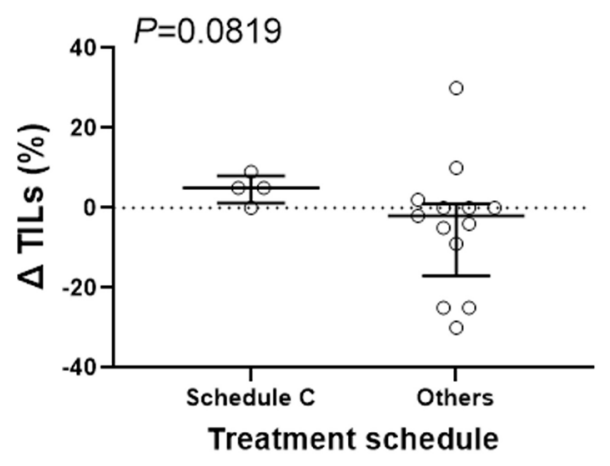

D

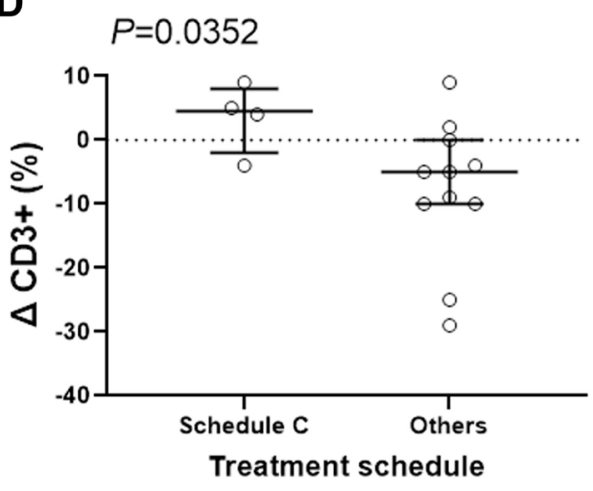

Figure 4: Treatment schedule affect infiltration of immune cells. Slides of core needle biopsies (pre-treatment) and from surgical specimens (post-treatment) were stained with hematoxylin \& eosin and an anti-CD-3 antibody and stromal TILs (A, B) and CD3-positive immune cells (C, D). Treatment schedules affect the percentage of TILs and CD3+ infiltrates differently using Kruskal-Wallis (A, C) and Mann-Whitney (B, D) test. Dunn's multiple comparisons test was used post hoc analysis and $P$ values for statistically significant differences are shown. Change in percentage of TILs and CD3+ cells for each subject together with median and interquartile range is shown. 
a significant reduction in the primary size of the tumor (Figure 5). Three patients, one from each treatment schedule B, C, and D reached pCR. No statistically significant differences in tumor size change was observed comparing the 5 treatment schedules (Figure 5 inset).

\section{DISCUSSION}

The main objective of our study was to determine an appropriate schedule to be used for adding the P10s-PADRE vaccine to cancer chemotherapy in the neoadjuvant setting considering the ability of the vaccine to elicit adequate antibody response. Three weekly immunizations with P10s-PADRE vaccine, added to NAC, were enough to generate antibodies in individuals treated in 5 different combination schedules. However, in one schedule, Schedule C, where the third immunization was administered a week before the first dose of chemotherapy, four out of 5 subjects responded, showing higher average fold increase in antibody titer. Therefore, the data indicate that the vaccine in combination with NAC is capable of generating antibody response early-on when administered immediately before standard-of-care chemotherapy. Establishing a high antibody titer quickly during patient treatment seems critical for combination with NAC. The follow-up data indicate that more subjects start to respond later into the cycles of NAC, emphasizing the immunological efficacy of the vaccine in combination with chemotherapy.

The majority of AEs were of grades 1 and 2, and all subjects fully completed their treatment. The safety data indicate that the combination therapy is feasible and welltolerated.

When we analyzed $\mathrm{CD}^{-} / \mathrm{CD}^{+} 6^{+}$cells among lymphocytes isolated from peripheral blood of the entire cohort, we found that the intensity of the CD16 expression was decreased after treatment. Analysis by schedule further revealed that treatment schedule affected CD16 expression, as subjects treated in schedule C, contrary to subjects in other schedules, showed an increase in the expression of CD16 on NK cells. The CD16 upregulation on NK cells in subjects enrolled in schedule $\mathrm{C}$ appears specific. CD16 can be a potent signal in elimination of antibody-coated tumor cells through ADCC, relevance of which should be investigated in future studies.

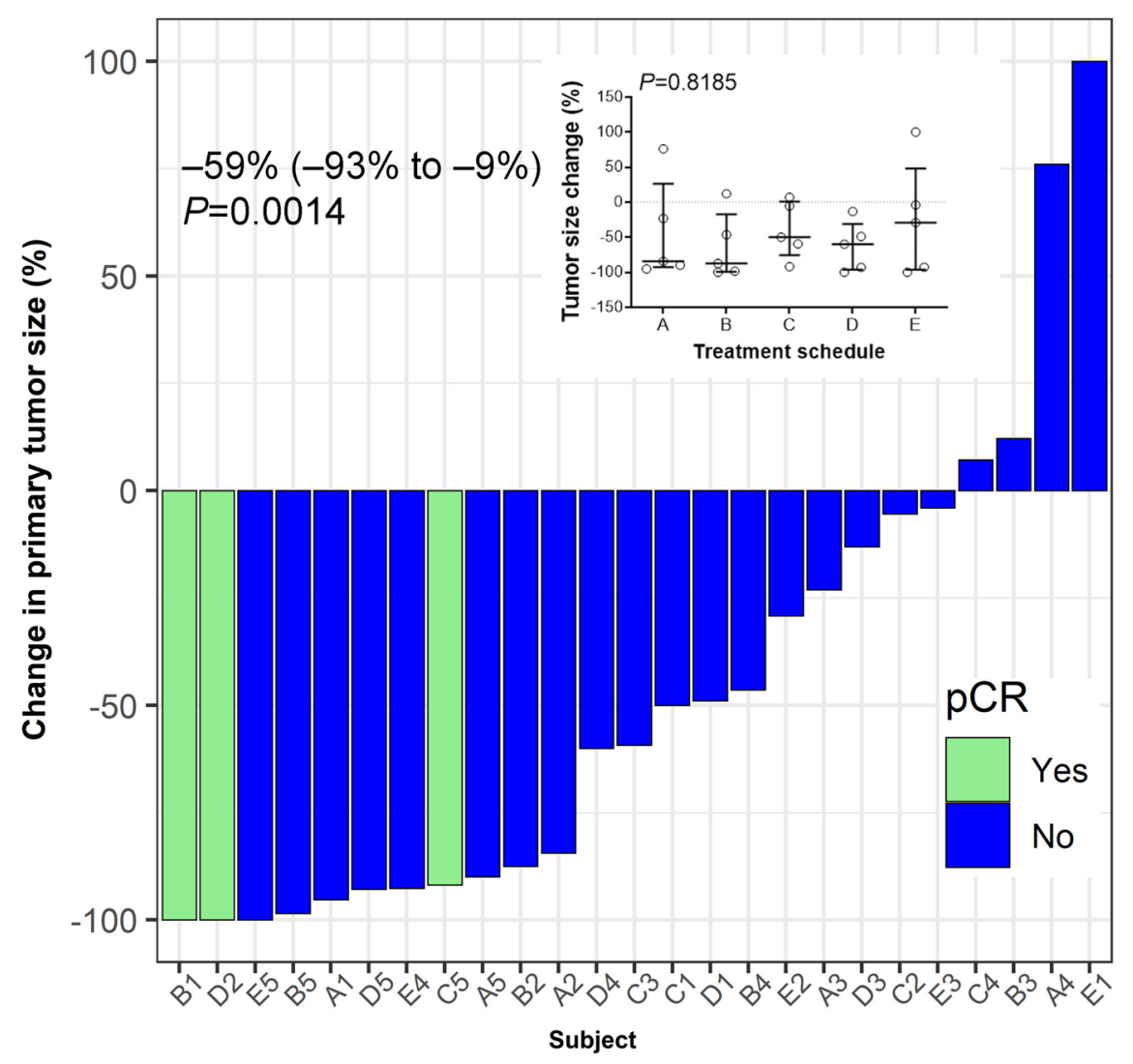

Figure 5: Tumor response to treatment. Hormone-receptor positive breast cancer patients were vaccinated for three consecutive weeks after enrolment in a neo-adjuvant setting. Pathological complete response (pCR) was defined as ypT0/Tis ypN0. Median (IQR, interquartile range) value of the percent change in the post-treatment tumor size from baseline at the time of surgery is shown. Wilcoxon's signed-rank test was used to examine the statistical significance of tumor size reduction $(P=0.0014)$. Inset summarizes percent tumor-size change based on treatment schedule. No significant differences between schedules are observed $(P=0.8185)$. Bars indicate median and interquartile range. 
Contrary to the CD16 expression levels, NKp46 and CD94 receptors showed an overall increase in expression levels in the entire cohort. NKp46 is also a major receptor mediating cytotoxicity in fresh peripheral-blood NK cells [21] and is involved in controlling metastasis in a melanoma animal model [22]. It plays a role in the cytotoxic ability of these cells that is independent of antibodies [21] as signaling through NKp46 leads to secretion of IFN- $\gamma$ and TNF- $\alpha$ [23] as well as other inflammatory cytokines that can directly affect tumor cells or ongoing adaptive immune responses [24]. No significant differences was observed between schedules regarding this marker suggesting a general response to the combination therapy. CD94 is another receptor family conserved in both mice and humans that can conjugate to most NKG2 family members [25]. CD94 can play both activation and inhibitory roles through conjugation with NKG2C or NKG2A [26]. Subjects in schedule C, show lower relative response to therapy in terms of CD94 expression. In our Phase I study performed on stage IV breast cancer patients [15], we have observed upregulation of NKp46 on NK cells upon immunization [16]. A role for the above markers in the efficacy of the combination therapy and their dependency on vaccination needs to be further investigated in future studies.

We observed higher IFN- $\gamma$ in subjects treated in schedule $\mathrm{B}$; the subjects that showed a significant reduction of CD16 expression. Others have shown that CD16 downregulation was associated with increased production of IFN- $\gamma$ [27]. However, we did not observe differences between schedule $\mathrm{C}$ and other schedules regarding the increase in IFN- $\gamma$ levels. The data suggest that the increase in IFN- $\gamma$, similar to NKp46, could be more of a consequence of the combination therapy. The activation of NK cells and an increase in IFN- $\gamma$ could be a part of immune response to the NAC alone that is strongly associated with pre-chemo immune features [9] that could be influenced by vaccination. These immune features have significant implication for cancer immunotherapy, as both NK cells and IFN- $\gamma$ release are considered major components of anti-cancer immune responses [28, 29]. The increase in IL-10, IL-6 and TNF- $\alpha$ though statistically significant, were small and not affected by treatment schedule.

Finally, we demonstrated that treatment schedules have different effect on the numbers of lymphocytes in the tumor microenvironment with schedule $\mathrm{C}$ showing higher increase in TILs in residual tumors after treatment. Promoting TILs may positively affect therapeutic modalities, improving long-term survival outcomes [10, 20]. The presence of TILs in residual disease after NAC was associated with better metastasis-free and overall survival [11]. Contrary to our expectation, we did not observe infiltration of NK cells. Instead, the data suggest an increase in stromal $\mathrm{CD} 3+\mathrm{T}$ cells in residual tumors after treatment. The attraction of $\mathrm{T}$ cells into the tumor environment is consistent with our preclinical data showing T-cell-dependent DTH response and a role for $\mathrm{T}$ cells in tumor shrinkage using P10-KLH vaccine [30]. Whether more TILs can contribute to better survival outcomes needs to be addressed in future studies. Lack of enough tissues prohibited identification of T-cell subsets that is a limitation of our study.

\section{MATERIALS AND METHODS}

\section{Study design}

We conducted a Phase Ib clinical trial to assess safety, tolerability and feasibility of adding the CMP vaccine, P10s-PADRE $[14,15]$, to a standard-of-care chemotherapy in breast cancer subjects. This trial was approved by the Institutional Review Board (IRB) of the University of Arkansas for Medical Sciences (UAMS), and was registered with the NIH clinical-trials registry at http://clinicaltrials.gov (NCT02229084). Women 18 years of age or older, of all races, with clinical stage I, II or III ER+/HER2- breast cancer were eligible, and subjects were enrolled after providing written informed consent. Eligibility criteria are described in Supplementary Table 1. The patients were recruited from the Breast Cancer Clinic at the Winthrop P. Rockefeller Cancer Institute at the UAMS campus, and from the Oncology Clinic of the Highlands Oncology Group in Northwest Arkansas.

\section{Vaccine preparation, immunization and treatment schedule}

P10s-PADRE was synthesized by AmbioPharm, Inc., (North Augusta, SC, USA) and administered with the adjuvant MONTANIDE ${ }^{\text {TM }}$ ISA 51 VG STERILE (SEPPIC, Inc., Fairfield, NJ, USA) as described before [15]. For this study, we considered five different vaccination schedules (5 subjects per schedule), named A, B, C, D, and $\mathrm{E}$, to evaluate the feasibility of eliciting an immune response when the vaccine was administered with NAC (Supplementary Table 2). The patients were immunized by administration of three weekly injections of P10s-PADRE vaccine at a dose of $500 \mu \mathrm{g}$. Patients were administered doxorubicin $\left(60 \mathrm{mg} / \mathrm{m}^{2}\right)$ and cyclophosphamide $(600$ $\mathrm{mg} / \mathrm{m}^{2}$ ) every three weeks for four cycles followed by docetaxel $\left(75 \mathrm{mg} / \mathrm{m}^{2}\right)$ every three weeks for four cycles. The timing of immunizations relative to chemotherapy and blood draws for each schedule is shown in Supplementary Table 2.

\section{Endpoint variables}

Safety and feasibility were the primary endpoints; assessing them was the primary objective. The 
immunological endpoints were anti-P10s antibody titers (primary) and NK cell activation (secondary). Tumor size was measured before treatment and at pathological examination after surgery, and change in the size of the primary tumor was calculated. Pathological examination and tumor measurements were performed blindly. Pathologic complete response (pCR) was defined as the absence of residual invasive cancer on histopathologic evaluation of paraffin-embedded tissue sections stained with hematoxylin and eosin of the complete resected breast specimen and all sampled regional lymph nodes following completion of the therapy (ypT0/Tis ypN0).

\section{Adverse event monitoring}

Adverse events were assessed using the NCI Common Terminology Criteria for Adverse Events (CTCAE), Version 4.0.

\section{Serum collection and ELISA}

Pre- and post-immunization serum samples were collected from each subject and anti-P10s-MAP IgG levels were measured via ELISA as described [14, 15]. The antibody titers were determined by measuring reactivity of 2-fold serial dilutions of both pre- and post-immune serum, and the fold change in anti-P10s-MAP IgG titer was determined in post-immune serum compared to baseline pre-immune serum.

\section{Cytokine measurement}

The Meso Scale Discovery ${ }^{\circledR}\left(\mathrm{MSD}^{\circledR}\right)$ multispot V-PLEX ${ }^{\circledR}$ assay system (Meso Scale diagnostics LLC, Rockville, MD, USA) was used to determine the levels of multiple cytokines in the serum samples collected according to manufacturer's instructions. The Proinflammatory Panel 1 (human) kit, which tests for IFN- $\gamma$, IL-1 $\beta$, IL-2, IL-4, IL-6, IL-8, IL-10, IL-12p70, IL-13, and TNF- $\alpha$, was used for cytokine measurements. The V-PLEX ${ }^{\circledR}$ assay plate was analyzed using the MSD Electrochemiluminescence charge-coupled device and QuickPlex SQ 120 imager and the results were reported using the Discovery Workbench 4.0 software.

\section{Isolation of peripheral blood mononuclear cells (PBMCs)}

PBMCs were isolated from freshly collected blood using Histopaque-1077 (Sigma). Blood was carefully layered onto the Histopaque-1077 at a ratio of $1: 1$ and centrifuged at room temperature for 30 minutes. Following centrifugation, the opaque interface containing mononuclear cells was collected. The cells were washed three times with PBS. Fresh cells were used for staining in flow cytometry.

\section{Flow cytometry}

Phenotypic studies were performed on isolated PBMCs by three-color flow cytometry using a BD LSRFortessa cytometer (BD Biosciences, San Jose, CA, USA), and analyzed using Flowjo ${ }^{\circledR}$ software (Flowjo LLC, Ashland, Oregon). Lymphocytes were gated and CD3-negative CD56-positive lymphocytes were selected for further detection of NK cell receptor expression. The expression of CD16 (FCGR3, Fc fragment of IgG receptor III), CD69, NKp46 and CD94 (KLRD1, killer cell lectin-like receptor D1) on CD3-negative/CD56positive cells was determined. The expression of CD69 on $\mathrm{CD} 3+$ and CD3+/CD56+ cells was also determined. All mAbs used for flow cytometry were purchased from BD Bioscienses (Becton, Dickinson and CompaFranklin lakes, NJ, USA).

\section{Tumor-infiltrating lymphocytes (TILs) and immunohistochemistry}

TILs were assessed using $\mathrm{H}$ and $\mathrm{E}$ slides in FFPE sections obtained through core needle biopsies prior to therapy and through surgical specimens after treatment at surgery. Separate individual slides were stained with anti-CD56 (123C3.D5 + 123A8, Abcam plc, Cambridge, MA), anti-CD3 (SP7, Abcam plc), anti-CD8 (SP16, Abcam plc), anti-FoxP3 (1054C, R and D systems), and anti-CD68 (KP1, Abcam plc) antibodies. All slides were prepared and stained by the UAMS pathology core. The percentage of TILs was determined according to the method proposed by the International Immuno-Oncology Working Group $[31,32]$. The same strategy was used to score various lymphocytes including CD56- and CD3positive TILs. Slides were independently evaluated by two pathologists (SPO and GRP). Images were analyzed using a Nikon Eclipse Ni microscope at 20X magnification. Photomicrographs were taken with a Nikon DS-Fi3 microscope camera using the NIS-Elements D software from Nikon.

\section{Statistical assessments}

All immune assays and evaluations of clinical endpoint were conducted blindly. Changes in immune indicators including antibody production, cytokine secretion and expression of NK markers were calculated and log-transformed for statistical analyses. GraphPad Prism 9 (San Diego, CA, USA) was used to conduct Wilcoxon signed-rank test, one-sample $t$-tests, and Kruskal-Wallis tests with post-hoc analyses using Dunn's multiple-comparison procedure. Fold increases in antiP10s peptide titer were analyzed using the 1-sided onesample $t$-test at $\alpha=0.05$ to compare mean fold increases against the null-hypothesis value of a 4 -fold increase. All other statistical tests were 2-sided at $\alpha=0.05$. 


\section{Ethics approval and consent to participate}

The clinical trial and all procedure were performed after approval by the UAMS IRB (reference number 202556) and in accordance with an assurance filed with and approved by the Department of Health and Human Services. The study is registered with the NIH clinicaltrials registry at http://clinicaltrials.gov (NCT02229084). Informed consent was obtained from all individuals included in the study.

\section{Consent for publication}

Subjects were consented for dissemination and communication of de-identified data generated in the study.

\section{Data availability}

All data relevant to the study are included in the article or provided as supplementary materials.

\section{CONCLUSIONS}

This Phase Ib clinical trial of the P10s-PADRE vaccine shows that immunization in combination with a standard-of-care NAC is feasible and well-tolerated. Combination therapy induces antibody response, stimulates activation of NK cells, and is associated with infiltration of $\mathrm{T}$ cells in tumor microenvironment. Randomized phase II trials focusing on treatment schedule $\mathrm{C}$ are needed to validate current findings and evaluate clinical efficacy.

\section{Abbreviations}

ADCC: antibody-dependent cell-mediated cytotoxicity; CMP: carbohydrate mimicking peptide; FCGR3: Fc fragment of IgG receptor III; HR+: hormone receptor-positive; HER2-: human Epidermal Receptor 2 negative; IgG: immunoglobulin G; IRB: institutional review board; KLRD1: killer cell lectin like receptor D1; NAC: neoadjuvant chemotherapy; NCAM1: neural cell adhesion molecule 1; NCR1: natural cytotoxicity triggering receptor 1; NK cells: natural killer cells; pCR: pathological complete response; PADRE: pan DR T helper epitope; SC: subcutaneous; TILs: tumor-infiltrating lymphocytes; UAMS: University of Arkansas for Medical Sciences.

\section{Author contributions}

S.M.I., F.J. and L.J.R. conducted the laboratory experiments. S.M.I. and J.J.L. conducted flow cytometry data analysis. M.A-R. supervised tissue slide preps and staining and participated in scoring of TILs and helped in data analysis. B.M-K supervised the conduct of experiments and together with E.R.S. conducted and supervised the statistical analyses. I.M., E.R.S., B.M-K., J.T.B. and T.K-E. designed the study. G.R.P. and S.P-O. reviewed $\mathrm{H}$ and $\mathrm{E}$ and immunohistochemistry slides, assessed TILs and determined TILs' lineage. J.T. B. and I.M. conducted the clinical trial and along with the other authors contributed to the writing of the manuscript.

\section{ACKNOWLEDGMENTS}

S.M.I. registered in the EMJMD LIVE (Erasmus + Mundus Joint Master Degree Leading International Vaccinology Education), co-funded by the EACEA (Education, Audiovisual and Culture Executive Agency) of the European commission, and received a scholarship from the EACEA.

\section{CONFLICTS OF INTEREST}

TKE and BMK are named as inventors on an institutional patent application filed by UAMS that is related to the content of this manuscript. Therefore, Drs. Kieber-Emmons, Monzavi-Karbassi, and UAMS have a potential financial interest in the vaccine used in this clinical trial. No financial or other support of any kind has resulted from this patent application. These financial interests have been reviewed and the clinical trial was performed by approved supervision in accordance with the UAMS conflict of interest policies. The other authors declare that they have no competing interests.

\section{FUNDING}

This work was supported by a Clinical Translational Award from the Department of Defense Breast Cancer Program (W81XWH-06-1-0542) to TKE. Also supported by Arkansas Biosciences Institute and the UAMS Translational Research Institute (TRI), UL1TR000039, U54 TR001629, and UL1 TR003107 through the NIH National Center for Research Resources and National Center for Advancing Translational Sciences and the UAMS Center for Microbial Pathogenesis and Host Inflammatory Responses, P20 GM103625.

\section{REFERENCES}

1. American Cancer Society. Breast Cancer Facts \& Figures 2019-2020. Atlanta: American Cancer Society, Inc. 2019.

2. Davies C, Pan H, Godwin J, Gray R, Arriagada R, Raina V, Abraham M, Medeiros Alencar VH, Badran A, Bonfill $\mathrm{X}$, Bradbury J, Clarke M, Collins R, et al. Long-term effects of continuing adjuvant tamoxifen to 10 years versus stopping at 5 years after diagnosis of oestrogen receptor-positive breast cancer: ATLAS, a randomised trial. 
Lancet. 2013; 381:805-16. https://doi.org/10.1016/S01406736(12)61963-1. [PubMed]

3. Blows FM, Driver KE, Schmidt MK, Broeks A, van Leeuwen FE, Wesseling J, Cheang MC, Gelmon K, Nielsen TO, Blomqvist C, Heikkilä P, Heikkinen T, Nevanlinna H, et al. Subtyping of breast cancer by immunohistochemistry to investigate a relationship between subtype and short and long term survival: a collaborative analysis of data for 10,159 cases from 12 studies. PLoS Med. 2010; 7:e1000279. https://doi.org/10.1371/journal.pmed.1000279. [PubMed]

4. Kennecke H, Yerushalmi R, Woods R, Cheang MC, Voduc D, Speers CH, Nielsen TO, Gelmon K. Metastatic behavior of breast cancer subtypes. J Clin Oncol. 2010; 28:3271-77. https://doi.org/10.1200/JCO.2009.25.9820. [ubMed]

5. Cardoso F, van't Veer LJ, Bogaerts J, Slaets L, Viale G, Delaloge S, Pierga JY, Brain E, Causeret S, DeLorenzi M, Glas AM, Golfinopoulos V, Goulioti T, et al. 70-Gene Signature as an Aid to Treatment Decisions in Early-Stage Breast Cancer. N Engl J Med. 2016; 375:717-29. https:// doi.org/10.1056/NEJMoa1602253. [PubMed]

6. Sparano JA, Gray RJ, Makower DF, Pritchard KI, Albain KS, Hayes DF, Geyer CE Jr, Dees EC, Goetz MP, Olson JA Jr, Lively T, Badve SS, Saphner TJ, et al. Adjuvant Chemotherapy Guided by a 21-Gene Expression Assay in Breast Cancer. N Engl J Med. 2018; 379:111-21. https:// doi.org/10.1056/NEJMoa1804710. [PubMed]

7. von Minckwitz G, Untch M, Blohmer JU, Costa SD, Eidtmann H, Fasching PA, Gerber B, Eiermann W, Hilfrich J, Huober J, Jackisch C, Kaufmann M, Konecny GE, et al. Definition and impact of pathologic complete response on prognosis after neoadjuvant chemotherapy in various intrinsic breast cancer subtypes. J Clin Oncol. 2012; 30:1796-804. https://doi.org/10.1200/JCO.2011.38.8595. [PubMed]

8. Waks AG, Stover DG, Guerriero JL, Dillon D, Barry WT, Gjini E, Hartl C, Lo W, Savoie J, Brock J, Wesolowski R, Li Z, Damicis A, et al. The Immune Microenvironment in Hormone Receptor-Positive Breast Cancer Before and After Preoperative Chemotherapy. Clin Cancer Res. 2019; 25:4644-55. https://doi.org/10.1158/1078-0432.CCR-190173. [PubMed]

9. Park YH, Lal S, Lee JE, Choi YL, Wen J, Ram S, Ding Y, Lee SH, Powell E, Lee SK, Yu JH, Ching KA, Nam JY, et al. Chemotherapy induces dynamic immune responses in breast cancers that impact treatment outcome. Nat Commun. 2020; 11:6175. https://doi.org/10.1038/s41467020-19933-0. [PubMed]

10. Lundgren C, Bendahl PO, Ekholm M, Fernö M, Forsare C, Krüger U, Nordenskjöld B, Stål O, Rydén L. Tumourinfiltrating lymphocytes as a prognostic and tamoxifen predictive marker in premenopausal breast cancer: data from a randomised trial with long-term follow-up. Breast Cancer Res. 2020; 22:140. https://doi.org/10.1186/s13058020-01364-w. [ubMed]
11. Dieci MV, Criscitiello C, Goubar A, Viale G, Conte P, Guarneri V, Ficarra G, Mathieu MC, Delaloge S, Curigliano G, Andre F. Prognostic value of tumorinfiltrating lymphocytes on residual disease after primary chemotherapy for triple-negative breast cancer: a retrospective multicenter study. Ann Oncol. 2014; 25:61118. https://doi.org/10.1093/annonc/mdt556. [PubMed]

12. Kieber-Emmons T, Luo P, Qiu J, Chang TY, O I, Blaszczyk-Thurin M, Steplewski Z. Vaccination with carbohydrate peptide mimotopes promotes anti-tumor responses. Nat Biotechnol. 1999; 17:660-65. https://doi. org/10.1038/10870. [PubMed]

13. Monzavi-Karbassi B, Luo P, Jousheghany F, TorresQuiñones M, Cunto-Amesty G, Artaud C, KieberEmmons T. A mimic of tumor rejection antigenassociated carbohydrates mediates an antitumor cellular response. Cancer Res. 2004; 64:2162-66. https://doi. org/10.1158/0008-5472.can-03-1532. [PubMed]

14. Makhoul I, Hutchins L, Emanuel PD, Pennisi A, Siegel E, Jousheghany F, Monzavi-Karbassi B, Kieber-Emmons T. Moving a Carbohydrate Mimetic Peptide into the clinic. Hum Vaccin Immunother. 2015; 11:37-44. https://doi. org/10.4161/hv.34300. [PubMed]

15. Hutchins LF, Makhoul I, Emanuel PD, Pennisi A, Siegel ER, Jousheghany F, Guo X, Pashov AD, MonzaviKarbassi B, Kieber-Emmons T. Targeting tumor-associated carbohydrate antigens: a phase I study of a carbohydrate mimetic-peptide vaccine in stage IV breast cancer subjects. Oncotarget. 2017; 8:99161-78. https://doi.org/10.18632/ oncotarget.21959. [ [PubMed]

16. Kieber-Emmons T, Makhoul I, Pennisi A, Emanuel PD, Hutchins LF, Siegel ER, Monzavi-Karbassi B. Unleashing natural killer cells upon immunization with a carbohydrate mimetic peptide vaccine. J Clin Oncol. 2018; 36:16. https:// doi.org/10.1200/JCO.2018.36.5 suppl.16.

17. Paul S, Lal G. The Molecular Mechanism of Natural Killer Cells Function and Its Importance in Cancer Immunotherapy. Front Immunol. 2017; 8:1124. https://doi. org/10.3389/fimmu.2017.01124. [PubMed]

18. Benson DM Jr, Bakan CE, Zhang S, Collins SM, Liang J, Srivastava S, Hofmeister CC, Efebera Y, Andre P, Romagne F, Bléry M, Bonnafous C, Zhang J, et al. IPH2101, a novel anti-inhibitory KIR antibody, and lenalidomide combine to enhance the natural killer cell versus multiple myeloma effect. Blood. 2011; 118:6387-91. https://doi.org/10.1182/ blood-2011-06-360255. [PubMed]

19. Delgado DC, Hank JA, Kolesar J, Lorentzen D, Gan J, Seo S, Kim K, Shusterman S, Gillies SD, Reisfeld RA, Yang R, Gadbaw B, DeSantes KB, et al. Genotypes of NK cell KIR receptors, their ligands, and Fc $\gamma$ receptors in the response of neuroblastoma patients to Hu14.18-IL2 immunotherapy. Cancer Res. 2010; 70:9554-61. https://doi. org/10.1158/0008-5472.CAN-10-2211. [PubMed]

20. Wang $\mathrm{K}, \mathrm{Xu} \mathrm{J}$, Zhang $\mathrm{T}$, Xue D. Tumor-infiltrating lymphocytes in breast cancer predict the response to 
chemotherapy and survival outcome: A meta-analysis. Oncotarget. 2016; 7:44288-98. https://doi.org/10.18632/ oncotarget.9988. [PubMed]

21. Sivori S, Pende D, Bottino C, Marcenaro E, Pessino A, Biassoni R, Moretta L, Moretta A. NKp46 is the major triggering receptor involved in the natural cytotoxicity of fresh or cultured human NK cells. Correlation between surface density of NKp46 and natural cytotoxicity against autologous, allogeneic or xenogeneic target cells. Eur J Immunol. 1999; 29:1656-66. https://doi. org/10.1002/(SICI)1521-4141(199905)29:05<1656::AIDIMMU1656>3.0.CO;2-1. [PubMed]

22. Glasner A, Ghadially H, Gur C, Stanietsky N, Tsukerman P, Enk J, Mandelboim O. Recognition and prevention of tumor metastasis by the NK receptor NKp46/NCR1. J Immunol. 2012; 188:2509-15. https://doi.org/10.4049/ jimmunol.1102461. [PubMed]

23. Glasner A, Levi A, Enk J, Isaacson B, Viukov S, Orlanski S, Scope A, Neuman T, Enk CD, Hanna JH, Sexl V, Jonjic $\mathrm{S}$, Seliger B, et al. NKp46 Receptor-Mediated Interferon- $\gamma$ Production by Natural Killer Cells Increases Fibronectin 1 to Alter Tumor Architecture and Control Metastasis. Immunity. 2018; 48:396-98. https://doi.org/10.1016/j. immuni.2018.01.010. [PubMed]

24. Moretta A, Marcenaro E, Parolini S, Ferlazzo G, Moretta L. NK cells at the interface between innate and adaptive immunity. Cell Death Differ. 2008; 15:226-33. https://doi. org/10.1038/sj.cdd.4402170. [PubMed]

25. Borrego F, Masilamani M, Marusina AI, Tang X, Coligan JE. The CD94/NKG2 family of receptors: from molecules and cells to clinical relevance. Immunol Res. 2006; 35:26378. https://doi.org/10.1385/IR:35:3:263. [PubMed]

26. Long EO, Kim HS, Liu D, Peterson ME, Rajagopalan S. Controlling natural killer cell responses: integration of signals for activation and inhibition. Annu Rev Immunol. 2013; 31:227-58. $\quad$ https://doi.org/10.1146/annurevimmunol-020711-075005. [PubMed]

27. Romee R, Foley B, Lenvik T, Wang Y, Zhang B, Ankarlo D, Luo X, Cooley S, Verneris M, Walcheck B, Miller J. NK cell CD16 surface expression and function is regulated by a disintegrin and metalloprotease-17 (ADAM17). Blood. 2013; 121:3599-608. https://doi.org/10.1182/ blood-2012-04-425397. [PubMed]
28. Shankaran V, Ikeda H, Bruce AT, White JM, Swanson PE, Old LJ, Schreiber RD. IFNgamma and lymphocytes prevent primary tumour development and shape tumour immunogenicity. Nature. 2001; 410:1107-11. https://doi. org/10.1038/35074122. [PubMed]

29. Giannopoulos A, Constantinides C, Fokaeas E, Stravodimos C, Giannopoulou M, Kyroudi A, Gounaris A. The immunomodulating effect of interferon-gamma intravesical instillations in preventing bladder cancer recurrence. Clin Cancer Res. 2003; 9:5550-58. [PubMed]

30. Wondimu A, Zhang T, Kieber-Emmons T, Gimotty P, Sproesser K, Somasundaram R, Ferrone S, Tsao CY, Herlyn D. Peptides mimicking GD2 ganglioside elicit cellular, humoral and tumor-protective immune responses in mice. Cancer Immunol Immunother. 2008; 57:1079-89. https:// doi.org/10.1007/s00262-007-0439-4. [PubMed]

31. Salgado R, Denkert C, Demaria S, Sirtaine N, Klauschen F, Pruneri G, Wienert S, Van den Eynden G, Baehner FL, Penault-Llorca F, Perez EA, Thompson EA, Symmans WF, et al. The evaluation of tumor-infiltrating lymphocytes (TILs) in breast cancer: recommendations by an International TILs Working Group 2014. Ann Oncol. 2015; 26:259-71. https://doi.org/10.1093/annonc/mdu450. [PubMed]

32. Dieci MV, Radosevic-Robin N, Fineberg S, van den Eynden G, Ternes N, Penault-Llorca F, Pruneri G, D’Alfonso TM, Demaria S, Castaneda C, Sanchez J, Badve S, Michiels $\mathrm{S}$, et al, and International Immuno-Oncology Biomarker Working Group on Breast Cancer. Update on tumorinfiltrating lymphocytes (TILs) in breast cancer, including recommendations to assess TILs in residual disease after neoadjuvant therapy and in carcinoma in situ: A report of the International Immuno-Oncology Biomarker Working Group on Breast Cancer. Semin Cancer Biol. 2018; 52:16-25. https://doi.org/10.1016/j.semcancer.2017.10.003. [PubMed] 